\title{
A Review of Chemotherapy and Radiotherapy Near the End of Life in Individuals with Metastatic Non-small Cell Lung Cancer
}

Research Article

Benjamin C. Li ${ }^{1 *}$, Stephanie M. Perkins ${ }^{2}$, Sharon E. Phillips ${ }^{3}$, Sara F. Martin ${ }^{4}$, Samantha Hsieh², Eric T. Shinohara ${ }^{1}$ Mark J. Stavas ${ }^{1}$

${ }^{1}$ Department of Radiation Oncology, Vanderbilt University Medical Center, Nashville, TN, 37232, USA

${ }^{2}$ Department of Radiation Oncology, Washington University School of

Medicine, St. Louis, MO 63110, USA

${ }^{3}$ Department of Biostatistics, Vanderbilt University Medical Center, Nashville,

TN, 37232, USA

${ }^{4}$ Department of Internal Medicine and Palliative Care, Vanderbilt University

Medical Center, Nashville, TN, 37232, USA

Received 14 July 2017; Accepted 5 November 2019

\begin{abstract}
Objectives: Appropriate chemotherapy and radiation near end of life is a moving target; challenged by increasing costs, evolving therapies, new reimbursement models and quality metrics. We review treatment trends and variables impacting the initiation of chemotherapy (CHT) and radiotherapy (XRT) in the final 60, 30 and 14 days of life in metastatic non-small cell lung cancer (NSCLC). Methods: The Florida Cancer Data System was studied to complete a retrospective cohort analysis of 48,858 individuals with Stage IV (M1) NSCLC from 1995-2010. We evaluated the initiation of CHT and XRT after diagnosis and associations with patient demographics, insurance and socioeconomic status (SES).

Results: The use of CHT increased from 35\% to 49\%, while XRT decreased from 52\% to 37\% between 1995 and 2010. Initial courses of CHT occurred $8.1 \%, 5.0 \%$, and $3.6 \%$ in the final 60,30 , and 14 days of life, and XRT $13.8 \%, 7.7 \%$, and $5.2 \%$ of the time, respectively. Younger, married, and male patients were more likely to receive treatment. Low SES (OR 0.685, 95\% $\mathrm{Cl} 0.633-0.741)$ and uninsured individuals (OR $0.678,95 \% \mathrm{CI} 0.572-0.804$ ) were less likely to receive $\mathrm{CHT}$. SES and insurance did not impact XRT.

Conclusions: The initiation of late CHT and XRT treatments decreased from 1995-2010. It persisted above $3 \%$ in the last 14 days of life. Clinicians may struggle to taper treatment before death, especially in patients with limited survival. It is important to recognize the complexities of death and dying and the potential influences of palliative care in affecting treatment decisions.
\end{abstract}

Keywords: End of life • chemotherapy • radiation • utilization • palliative care

\section{Introduction}

Advancements in cancer therapies and the integration of palliative care have contributed greatly to improvements in quality of life and survival for individuals with metastatic non-small cell lung cancer (NSCLC). However, as healthcare costs escalate and providers shift toward value-based care, the debate remains about the appropriate utilization of medical resources near the end of life. This issue is compounded by the increasing burden of cancer in the population. Given the current trends, U.S. costs of cancer care are expected to reach $\$ 174$ billion by 2020 , a $39 \%$ increase since 2010 . $^{(1)}$

The majority of cancer costs are incurred during the final months of life. During this time, the appropriate delivery of chemotherapy and radiation remains a challenge due to difficulties with prognostication and a sparsity of evidence-based guidelines. ${ }^{(2-5)}$ Prior 
studies have shown that up to $25 \%$ of cancer patients getting chemotherapy and/or radiation near the end of life are treated without clear benefits. ${ }^{(6-8)}$ While, the intention of thoracic radiation near the end of life is presumably palliative, even the tolerance of a short course of palliative thoracic radiation for moderate symptoms (cough, hemoptysis, thoracic pain, dyspnea, hoarseness or dysphagia) may be poor and nonbeneficial, compared to best supportive care. ${ }^{(9)}$ In many cases, symptoms may be palliated by means other than chemotherapy or radiation. Nonetheless, it is unclear to call this over utilization in the setting of diagnoses when new patients are functionally limited, but motivated to try treatment regardless.

In the midst of our understanding, contemporary discussions amongst oncologists and a growing body of evidence are establishing improved outcomes and reduced costs with the integration of palliative care for advanced cancer patients. Guidelines put forth by the Choosing Wisely Campaign, American Society of Clinical Oncology (ASCO) and the National Quality Forum (NQF) recommend early integration of palliative care to potentially achieve better quality of life, patient satisfaction, caregiver burden and even survival.(10) New palliative oncology specialist services may change utilization patterns of chemotherapy and radiation near the end of life, offering more timely treatment or reducing the number of over-aggressive treatments close to death. ${ }^{(11)}$ This may help reduce "aggressive treatments", or those which are costly and/or do little to improve survival or quality of life before death.

In the next several years, states and regions across the globe will be called to manage larger burdens of cancer, especially among the elderly. In light of care quality and cost, it is important to consider the treatment rates and variables impacting the end of life management. In particular, treatments initiated in the last 14 days of life generally adds little value - or can be detrimental - to patient care. To understand the trend of modern treatment patterns near the end of life, we study Florida, which has the largest portion of elderly patients and second-highest total Medicare enrollees in the country. ${ }^{(12)}$

As cancer care develops, the initiation of chemotherapy and radiotherapy should decrease in the last days of life for which the marginal benefit becomes questionable. Barring prognostic limitations, we believe that initial courses of treatment should taper near the end of life (e.g., less people starting treatment 0-14 days from death than 15-30 days from death). This study reviews the longitudinal trends of cancer treatment surrounding the final weeks of life. We discern relevant socioeconomic factors that impact the utilization of resources near the end of life. Given the shift to value- based care, we provide valuable awareness towards the timing of clinical decisions near the end of life in terminal cancer patients.

\section{Methods}

We performed a retrospective cohort analysis of individuals diagnosed with Stage IV (M1) NSCLC between 1995 and 2010 using the Florida Cancer Data System (FCDS). All individuals resided in the state of Florida and were over the age of 18 years at the time. This data was obtained from the State of Florida Department of Health, which contracts the FCDS housed at the University of Miami. The FCDS is a populationbased cancer registry with gold-level certification from the North American Association of Central Cancer Registries since 1996. ${ }^{(13)}$ With few exceptions, all cancer cases diagnosed or treated in Florida (since 1981) are reported to the FCDS, regardless of insurance and medical provider. The FCDS collects information on diagnosis, stage of disease, patient demographics, residence and methods of treatment. ${ }^{(14)}$

The FCDS records the first treatment courses of chemotherapy and radiation for each patient after Stage IV diagnosis. We studied all initial treatments of chemotherapy and radiotherapy and included a time-series analysis for every two-year period. We categorized treatments as occurring in the last 14, 30, 60 , or greater than 60 days of life.

Our main analysis does not capture treatments after the first course. Therefore, those with early initial treatments may have had undocumented later courses of treatment in the FCDS. However, patients with a small survival window are more likely to have their first course of treatment be their last. To study differences in this population and better understand near-end-of-life utilization rates, we performed an extra subset analysis that included only those who died 60 days or less after diagnosis.

Statistical analysis was performed using $\mathrm{R}$ version 3.0.2. Univariate statistics were run to quantify patient characteristics. Continuous variables were compared using the Wilcoxon rank sum test, while categorical variables were compared using Pearson's Chi-Square test. All univariate tests were two-tailed, with a p-value of $\leq 0.05$ considered significant. Logistic regression models were run to determine the association between insurance types, socioeconomic status (SES), marital status, sex, age at diagnosis and the receipt of chemotherapy and radiation. Those from residences in which $<5 \%, 5-20 \%$, or $20-100 \%$ of neighborhood households fell below the federal poverty level were considered high, middle, or 
Iow SES, respectively. Survival times were computed using Kaplan-Meier estimate.

\section{Results}

\subsection{Patient Characteristics}

We evaluated 48,858 patients who met the inclusion criteria for this study. Patient characteristics are shown in Table 1 . The $25^{\text {th }}, 50^{\text {th }}$ and $75^{\text {th }}$ quartiles for age at diagnosis were 60, 69 and 76 years, respectively. The quartiles for survival time were 2.4 months, 4.8 months and 12 months. $56 \%$ of patients were married, $17 \%$ widowed, $13 \%$ single, $11 \%$ divorced and 3\% unknown. Patients were $14 \%$ high SES, $68 \%$ middle SES and $17 \%$ low SES. The total population with insurance was $81 \%$. Of those insured, Medicare comprised 66\%, Private $25 \%$, Medicaid $6 \%$ and Military $2 \%$.

\subsection{Chemotherapy and Radiotherapy Treatment Patterns}

Time trends of percent utilization are shown in Figure 1. A total of 21,573 patients received chemotherapy and 21,633 patients received radiotherapy. From 1995 to 2010 , chemotherapy use increased from $35 \%$ to $49 \%$ of cases, while radiotherapy use decreased from $52 \%$ to $37 \%$. Recommended treatment was refused by $3 \%$ of chemotherapy patients $(\mathrm{N}=703)$ and less than $1 \%$ of radiotherapy patients $(\mathrm{N}=137)$.

When treated, 11,983 patients received both chemotherapy and radiotherapy before death. Of these, $27 \%$ received concurrent treatment, $40 \%$ received chemotherapy first and $33 \%$ received radiation first. Besides these, 9,590 patients received chemotherapy without radiotherapy, and 9,650 patients received radiotherapy without chemotherapy. The median time from diagnosis to the start of chemotherapy was 20 days, and from diagnosis to the start of radiation was 26 days. The median time from the start of chemotherapy to death was 192 days, and from the start of radiotherapy to death was 130 days. 17,635 patients did not receive chemotherapy or radiotherapy.

Treatment near the end of life was divided into intervals of 0-14 days, 15-30 days, 31-60 days, and $>60$ days from death in Table 2. From 1995 to 2010, chemotherapy patients ( $N=21,573)$ grew less likely to start their first chemotherapy treatment in the last 14,30 and 60 days of life. Chemotherapy treatment in the last $0-14$ days decreased from $4.0 \%$ to $3.2 \%$, $15-30$ days decreased from $5.2 \%$ to $3.9 \%$, and $31-60$

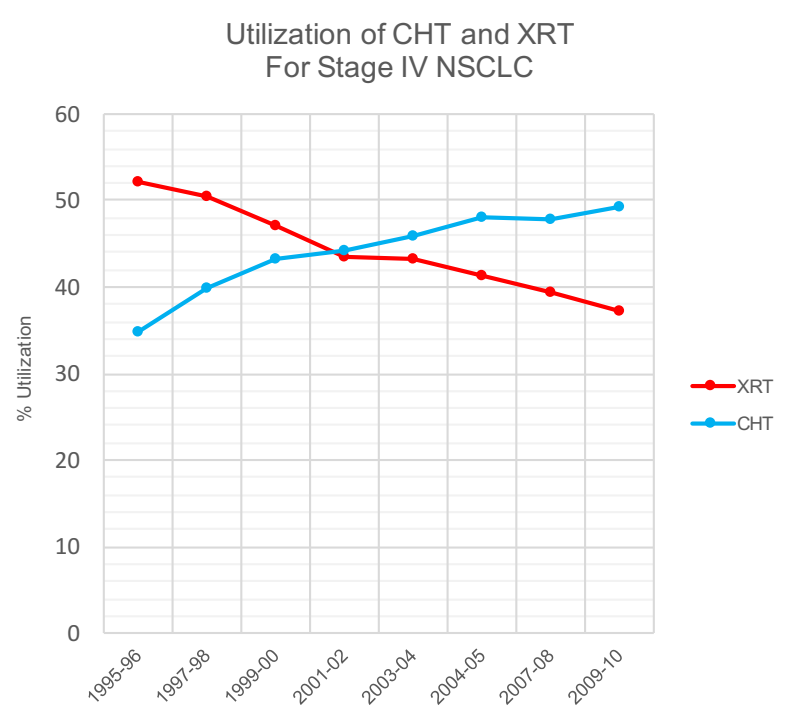

Figure 1: Utilization of $\mathrm{CHT}$ and XRT. The percentage of patients that initiated chemotherapy and radiotherapy any time after diagnosis of Stage IV NSCLC is shown. Trends are shown in two-year time frames between 1995 and 2010

days decreased from $9.2 \%$ to $7.7 \%$. During this time, radiotherapy patients $(\mathrm{N}=21,633)$ also grew less likely to start their first radiation treatment in the last 14,30 , and 60 days of life. Radiation treatment in the last 0-14 days decreased from $5.8 \%$ to $4.0 \%, 15-30$ days decreased from $7.3 \%$ to $7.0 \%$, and $31-60$ days decreased from $14 \%$ to $12.6 \%$.

\subsection{Subset Analysis in 60-Day Limited Survival}

Within our study, 12,910 (26\%) patients met the criteria for our subset analysis, which included only those patients who survived less than 60 days after diagnosis. In total, $3,660(28 \%)$ and $1,991(15 \%)$ received radiotherapy and chemotherapy, respectively. The initiation of chemotherapy and radiation treatments for these patients is shown in Figure 2. Usage of radiotherapy decreased from $35 \%$ in 1995 to $21 \%$ in 2010 . On the other hand, the use of chemotherapy remained even at $15 \%$. Overall, initiation in the last 60,30 and 14 days of life was $28 \%, 18 \%$ and $8 \%$ for radiotherapy and $15 \%$, $10 \%$ and $5 \%$ for chemotherapy, respectively.

\subsection{Socioeconomic Factors Impacting Treatment}

Factors associated with the treatment are highlighted in Table 3. Individuals receiving chemotherapy were 
Table 1: Patient Characteristics.

\begin{tabular}{|c|c|c|c|}
\hline Characteristic & Diagnosed Patients & CHT Treatment & XRT Treatment \\
\hline Age at Diagnosis (years) \pm quartiles & $60 \quad 69 \quad 76$ & -- & -- \\
\hline Survival after Diagnosis (months) & $2.4 \quad 4.8 \quad 12.0$ & - - & -- \\
\hline Diagnosis to Treatment (months) & -- & 0.40 .91 .5 & $\begin{array}{lll}0.3 & 0.7 & 1.4\end{array}$ \\
\hline Treatment to Death (months) & -- & 2.86 .413 .2 & $\begin{array}{lll}1.8 & 4.3 & 10.0\end{array}$ \\
\hline Male | Female & $58 \% \mid 42 \%$ & $58 \% \mid 42 \%$ & $60 \% \mid 40 \%$ \\
\hline \multirow[t]{2}{*}{ White | Non-White } & $83 \% \mid 17 \%$ & & \\
\hline & & $\%$ CHT Treated & \% XRT Treated \\
\hline Patients Diagnosed 1995 to 2010 & $N=48,858$ & $44 \%$ & $44 \%$ \\
\hline \multicolumn{4}{|l|}{ Treatment Before Death } \\
\hline $\mathrm{CHT}$ and $\mathrm{XRT}$ & 11,983 & $100 \%$ & $100 \%$ \\
\hline $\mathrm{CHT}$ and not XRT & 9,590 & $100 \%$ & $0 \%$ \\
\hline XRT and not CHT & 9,650 & $0 \%$ & $100 \%$ \\
\hline Neither & 17,635 & $0 \%$ & $0 \%$ \\
\hline \multicolumn{4}{|l|}{ Marital Status } \\
\hline Married & 27,592 & $49 \%$ & $46 \%$ \\
\hline Widowed & 8,180 & $32 \%$ & $36 \%$ \\
\hline Single & 6,152 & $42 \%$ & $45 \%$ \\
\hline Divorced & 5,586 & $44 \%$ & $47 \%$ \\
\hline Unknown & 1,348 & $38 \%$ & $46 \%$ \\
\hline \multicolumn{4}{|l|}{ SES } \\
\hline Low & 6,901 & $50 \%$ & $45 \%$ \\
\hline Middle & 33,430 & $44 \%$ & $44 \%$ \\
\hline High & 8,527 & $40 \%$ & $46 \%$ \\
\hline \multicolumn{4}{|l|}{ Insurance Status } \\
\hline Insured & 39,575 & $44 \%$ & $43 \%$ \\
\hline Medicare & 26,302 & $39 \%$ & $39 \%$ \\
\hline Private & 9,947 & $55 \%$ & $48 \%$ \\
\hline Medicaid & 2,476 & $48 \%$ & $52 \%$ \\
\hline Military & 895 & $45 \%$ & $58 \%$ \\
\hline Not insured & 2,443 & $42 \%$ & $48 \%$ \\
\hline Unknown & 6,840 & $46 \%$ & $51 \%$ \\
\hline
\end{tabular}

Table 2: Timing of treatment initiation in Stage IV NSCLC Patients from 1995 - 2010.

\begin{tabular}{|c|c|c|c|c|c|c|c|c|c|}
\hline Years: & $95-96$ & 97-98 & $99-00$ & 01-02 & $03-04$ & $05-06$ & $07-08$ & $09-10$ & Total \\
\hline & \multicolumn{9}{|c|}{ Patients who initiated first course of radiotherapy } \\
\hline$>60$ days from death & $72.9 \%$ & $73.9 \%$ & $72.3 \%$ & $72.6 \%$ & $73.4 \%$ & $72.9 \%$ & $72.3 \%$ & $76.3 \%$ & $73.3 \%$ \\
\hline $31-60$ days from death & $14.0 \%$ & $12.9 \%$ & $15.1 \%$ & $14.3 \%$ & $13.2 \%$ & $14.0 \%$ & $14.7 \%$ & $12.6 \%$ & $13.8 \%$ \\
\hline $15-30$ days from death & $7.3 \%$ & $8.3 \%$ & $7.4 \%$ & $7.8 \%$ & $7.9 \%$ & $7.5 \%$ & $7.9 \%$ & $7.0 \%$ & $7.7 \%$ \\
\hline \multirow[t]{2}{*}{$0-14$ days from death } & $5.8 \%$ & $5.0 \%$ & $5.1 \%$ & $5.3 \%$ & $5.6 \%$ & $5.6 \%$ & $5.1 \%$ & $4.0 \%$ & $5.2 \%$ \\
\hline & \multicolumn{9}{|c|}{ Patients who initiated first course of chemotherapy } \\
\hline$>60$ days from death & $81.6 \%$ & $82.7 \%$ & $82.7 \%$ & $82.6 \%$ & $83.4 \%$ & $84.0 \%$ & $83.7 \%$ & $85.2 \%$ & 83.3\% \\
\hline 31- 60 days from death & $9.2 \%$ & $8.3 \%$ & $9.0 \%$ & $9.5 \%$ & $8.7 \%$ & $8.5 \%$ & $8.8 \%$ & $7.7 \%$ & $8.1 \%$ \\
\hline $15-30$ days from death & $5.2 \%$ & $5.3 \%$ & $5.1 \%$ & $4.5 \%$ & $4.1 \%$ & $4.8 \%$ & $4.4 \%$ & $3.9 \%$ & $5.0 \%$ \\
\hline $0-14$ days from death & $4.0 \%$ & $3.8 \%$ & $3.2 \%$ & $3.4 \%$ & $3.7 \%$ & $2.7 \%$ & $3.1 \%$ & $3.2 \%$ & $3.6 \%$ \\
\hline
\end{tabular}


Initiation of Treatments for Stage IV NSCLC

in 60-Day Limited Survival

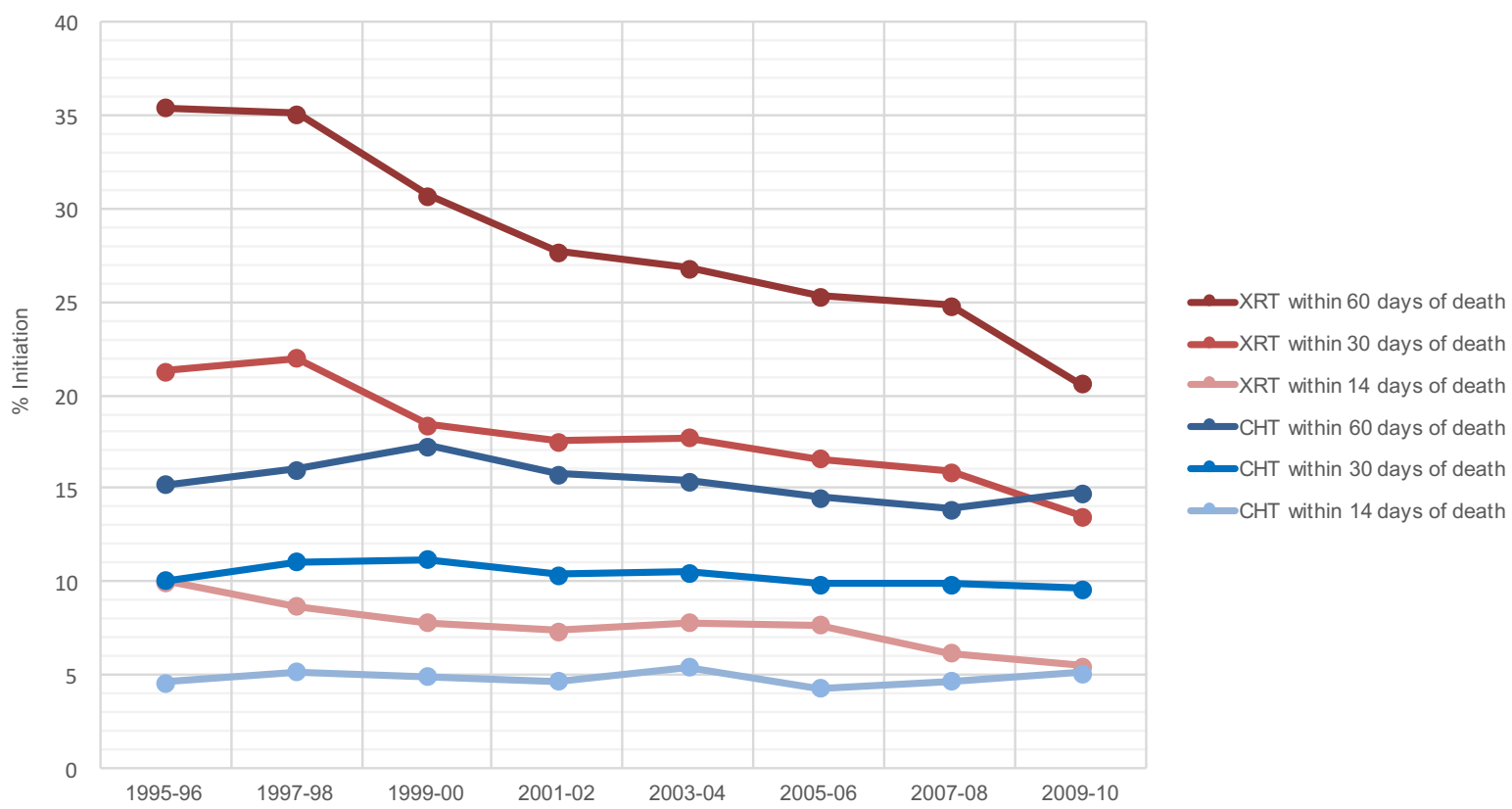

Figure 2: Initiation of Treatments for Stage IV NSCLC in 60-Day Limited Survival. Only patients with a 60-day or less survival from date of diagnosis to date of death are included. The percentage of patients that initiated radiotherapy (red lines) and chemotherapy (blue lines) within each time frame after diagnosis of Stage IV NSCLC is shown: within 60 days of death, within 30 days of death, and within 14 days of death. Trends are shown in two-year time frames between 1995 and 2010

Table 3: Factors Impacting Utilization.

\begin{tabular}{|c|c|c|c|}
\hline \multicolumn{4}{|c|}{ Radiotherapy Received } \\
\hline Characteristic & OR & $95 \% \mathrm{Cl}$ & P (Wald statistics) \\
\hline Age 70: 65 & 0.897 & $(0.887,0.908)$ & $<0.0001$ \\
\hline Low SES: Middle SES & 1.015 & $(0.959,1.074)$ & \multirow{2}{*}{0.173} \\
\hline Low SES: High SES & 1.073 & $(0.992,1.160)$ & \\
\hline Not Married: Married & 0.938 & $(0.896,0.982)$ & 0.006 \\
\hline Not Insured: Insured & 0.852 & $(0.721,1.007)$ & $<0.0001$ \\
\hline Female: Male & 0.863 & $(0.826,0.903)$ & $<0.0001$ \\
\hline CHT Received-Yes: No & 0.593 & $(0.567,0.619)$ & $<0.0001$ \\
\hline \multicolumn{4}{|c|}{ Chemotherapy Received } \\
\hline Characteristic & OR & $95 \% \mathrm{Cl}$ & P (Wald Statistics) \\
\hline Age 70: 65 & 0.824 & $(0.814,0.834)$ & $<0.0001$ \\
\hline Low SES: Middle SES & 0.830 & $(0.783,0.880)$ & \multirow{2}{*}{$<0.0001$} \\
\hline Low SES: High SES & 0.681 & $(0.629,0.738)$ & \\
\hline Not Married: Married & 0.702 & $(0.671,0.736)$ & $<0.0001$ \\
\hline Not Insured: Insured & 0.678 & $(0.572,0.804)$ & $<0.0001$ \\
\hline Female: Male & 1.077 & $(1.029,1.127)$ & 0.001 \\
\hline XRT Received-Yes: No & 0.593 & $(0.568,0.620)$ & $<0.0001$ \\
\hline
\end{tabular}


less likely to receive radiotherapy and vice versa. Older individuals were less likely to receive radiotherapy and chemotherapy. Individuals that were classified as not married (single, divorced, widowed) were less likely to receive radiotherapy (OR $0.938 ; 95 \% \mathrm{Cl} 0.896,0.982$ ) and chemotherapy (OR 0.702; 95\% Cl 0.671, 0.736). Widowed patients accounted for the greatest difference in receiving chemotherapy ( $32 \%$ vs. $49 \%$ married) and radiotherapy ( $36 \%$ vs. $46 \%$ married).

SES did not impact the odds of receiving radiotherapy, while low SES patients (measured as individuals living in high poverty areas) were less likely to receive $\mathrm{CHT}$ (OR, 0.685, 95\% Cl, 0.633-0.741). Insurance status did not impact the odds of receiving radiotherapy (OR $0.852 ; 95 \% \mathrm{Cl} 0.721,1.007)$ but it did affect chemotherapy (OR 0.678; 95\% Cl 0.572, 0.804). Between Medicare and privately insured patients, there was no difference in the odds of receiving radiotherapy (OR 1.014, 95\% Cl 0.954, 1.079) or chemotherapy (OR $0.957 ; 95 \% \mathrm{Cl} 0.898,1.019)$. However, military patients were significantly more likely to receive radiotherapy (OR 1.434, 95\% Cl 1.220, 1.686) and less likely to receive chemotherapy (OR $0.698,95 \% \quad \mathrm{Cl} 0.594$, 0.821 ) compared to privately insured patients. Medicaid patients were also more likely to receive radiotherapy (OR 1.191, 95\% Cl 1.070, 1.326) and less likely to receive chemotherapy (OR $0.758,95 \% \mathrm{Cl} 0.679,0.845$ ) than privately insured patients. Females were less likely to receive radiotherapy (OR $0.863 ; 95 \% \mathrm{Cl} 0.826$, $0.903)$, and slightly more likely to receive chemotherapy (OR 1.077; 95\% Cl 1.029, 1.127).

\section{Discussion}

Clinical management near the end of life is an ongoing challenge. Limited studies exist regarding treatment utilization, which tend to be single-institution or singlepayer based and may be biased by individual physician or payer preferences. Our study reviews the Florida state-wide registry, which includes a broad patient, provider and payer mix. In doing so, we capture the modern large-scale trends surrounding advanced cancer care. Furthermore, we believe that identifying the initiation of treatments provides valuable new awareness towards the timing of clinical decisions near the end of life in terminal cancer patients.

Among our 48,585-patient cohort from 1995 to 2010, the utilization of chemotherapy increased from 35\% to $49 \%$. The increased use of chemotherapy was likely due to improvements in treatment options, including targeted agents and tolerability. Although chemotherapy was used more often, the proportion of individuals initiating chemotherapy near the end of life decreased. By 2010, chemotherapy treatments were initiated 3160 days from death $7.7 \%$ of the time, $15-30$ days from death $3.9 \%$ of the time, and $0-14$ days from death $3.2 \%$ of the time.

On the other hand, radiotherapy utilization decreased from $52 \%$ to $37 \%$ of cases. The proportion of individuals initiating radiotherapy near the end of life also decreased. By 2010, radiotherapy treatments were initiated $31-60$ days from death $12.6 \%$ of the time, 1530 days from death $7.0 \%$ of the time, and $0-14$ days from death $4.0 \%$ of the time. These results also show that initial radiotherapy treatments occurred closer to death than chemotherapy treatments.

Our figures are similar to a large Medicare-based study in 2004, which found that $9 \%$ of cancer decedents received chemotherapy in their last month of life. ${ }^{(15)}$ Our findings are also comparable to other near-end-of-life radiation studies, ${ }^{(16-18)}$ whose rates of radiation utilization ranged from 7.6 to $10.3 \%$ in the last 30 days of life and 4.2 to $10 \%$ in the last 14 days of life.

We also conducted a subset analysis, which considered 12,910 patients that had a relatively small window of survival (60 days or less). This way, each patient's first course of treatment was likely to have been their last. From 1995 to 2010, radiotherapy utilization in 60 -day limited survival decreased from $35 \%$ to $21 \%$ of cases. The average utilization rate was $18 \%$ in the last 30 days and $8 \%$ in the last 14 days of life. On the other hand, chemotherapy utilization in 60-day limited survival remained at $15 \%$ from 1995 to 2010 . The chemotherapy utilization rate was $10 \%$ in the last 30 days and $5 \%$ in the last 14 days of life. As the marginal benefit of treatment decreases, the use of CHT or XRT should become tapered in the last 30 and 14 days of life. However, an equal number of chemotherapy patients initiated treatment in the last 14 days of life compared to the last 15-30 days of life. The appropriate tapering of treatment may be difficult in patients with 60-day limited survival, given these patients likely presented later in their illness or struggled with more rampant disease compared to our primary cohort.

In total, $3.6 \%$ and $5.2 \%$ of chemotherapy and radiation courses are initiated in the last 14 days of life, when patients are unlikely to experience clinical benefit from treatment. These treatments are costly to patients and payers, have risks for side effects and complications, and can be stressful for patients, providers and caregivers. This point underlies our discussion regarding appropriate utilization of resources in patients with imminent death, those most vulnerable to quick treatment decisions, and those who suffer from inaccurate prognostication. 
Our review illustrates the modern paradigm that palliative treatment is accepted by nearly all patients to whom it is offered. In our analysis, 31,223 (63.9\%) patients received some form of chemotherapy or radiotherapy after diagnosis, whereas recommended treatment was refused by only a very small number of patients - just 703 chemotherapy and 137 radiotherapy patients. Previous studies have demonstrated that $64-81 \%$ of patients do not understand that palliative treatment is not curative for their stage IV cancer. $(19,20)$ Without clear communication, physicians are in a dangerous position to prescribe treatments near the end of life whose benefits may be unclear to patients.

We explored individual factors that impacted the odds of receiving chemotherapy and radiotherapy. Uninsured individuals and those living in impoverished areas were less likely to receive chemotherapy. On the other hand, the odds of receiving radiotherapy were independent of SES and insurance status. Possible explanations include the medical and logistical differences between chemotherapy and radiation. Whereas higher performance status is required for chemotherapy and often includes frequent follow-up and laboratory studies, palliative radiotherapy is typically a shorter treatment course (for instance, one fraction for the palliation of bone metastases), requires less visits and remains an option even for patients with poor performance status. Data on the effects of SES and access to palliative care are limited but emerging. ${ }^{(21)}$ Notably, performance status is not a variable recorded in the FCDS, and this limitation alone may reduce prognostic awareness and influence over utilization by oncology providers for either treatment modality. Married individuals were more likely to receive treatments, which could reflect the social support often required for treatment. On average, caregivers provide 8 hours of daily assistance including personal care, symptoms management, transportation and care coordination for individuals with advanced cancer.(22) Earlier integration of palliative care may improve quality of life, depression and stress burden for caregivers. ${ }^{(23)}$

Despite improvement efforts, overtreatment near the end of life is an ongoing debate complicated by multiple factors including the heterogeneity of cancer and inadequacies with prognostication. Several studies have demonstrated that physicians are overly optimistic by a time factor of two to five-fold. ${ }^{(2-5)}$ Patients and physicians often share intrinsic biases; overestimating the benefits of treatment and preserving the inherent desire to do "everything possible".(24-26) Moreover, patients are willing to suffer large treatment toxicities for marginal gains. ${ }^{(27)}$

The evolution of metastatic disease can be tumultuous, whereas the current prognostication tools, such as performance status, are subject to bias and limitations. For instance, there are data in geriatric oncology where patients have a good performance status but limited ability to tolerate the physiologic burden of tumor-directed therapy and decline quickly after initiating treatment. ${ }^{(28)}$ Calls for improvement have been made. ${ }^{(29,30)}$ In addition to the prognostic challenges, there are several institutional barriers that limit the integration of hospice and palliative care. These include insurance mandates, cost constraints, limited resources, as well as physician buy-in for palliative services. ${ }^{(31-33)}$

In light of the aforementioned realities, "overutilization" of chemotherapy and radiation are foreseeable issues. Cautious tones should be used when defining appropriate and inappropriate care, particularly when shared decision making and informed consent have occurred. Quality metrics put forth by the National Quality Forum and Choosing Wisely Campaign ${ }^{\circledR}$ recommend palliative care for any individual with a terminal illness who has physical, psychological, social or spiritual distress. ${ }^{(34)}$ These guidelines also state that chemotherapy should not be given within 14 days of death, while there are no guidelines on the optimal timing of palliative radiation. In this study, $2-8 \%$ of individuals started radiation and $2-5 \%$ started chemotherapy within 14 days of death. Given the complex bio-psycho-socialspiritual dimensions of death and dying, it may not be reasonable to expect these numbers to drop significantly further. Yet, as accountability care organizations expand and insurance reimbursement structures rely more on quality metrics, we are called to address our own standards for cancer care. ${ }^{(35-37)}$

Standardized management near the end of life is challenged further by rapidly evolving therapies. The first immunotherapy agents (Nivolumab and Pembrolizumab) were FDA-approved for NSCLC in 2015 and have had dramatic implications in survival outcomes. This study observes treatment patterns in the pre-immunotherapy era from 1995-2010. Future directions should evaluate and compare near-end-of-life radiotherapy utilization pre- and post- pervasive adoption of immunotherapy for patients with advanced NSCLC, and its implications for the discussion with the patient.

It has been shown that end of life discussions significantly reduce over-aggressive medical interventions near the time of death and even improve survival. Also, it has been well documented that additional education in these areas is needed for our trainees. ${ }^{(15,38,39)}$ Perhaps, there should be less focus on utilization percentages and more focus on patient centered discussions that influence decision-making. If a patient and physician carefully discuss prognosis, goals of care and treatment options, and the patient decides 
to proceed with therapy, is this a misappropriation of medical resources? Rather than try to base quality of care on the timing of radiotherapy, perhaps the primary measure should be goals of care discussions documented with patients. As we examine treatment utilization patterns as an area for reform, especially for high-risk individuals, the oncologist's careful, focused and thoughtful care should be targeted to all patients facing terminal illness.

\subsection{Study Limitations}

Clinicians continue to struggle with accurate prognostication; therefore, treatment decisions may be influenced by estimated survivability before death. There are multiple confounding variables that predict disease outcomes and these impact recommendations for or against conventional treatment modalities, including disease burden and site, comorbidities, molecular characteristics, and performance status. As mentioned in our discussion, the FCDS does not record performance status, and this study does not capture those intricacies.

The use of radiation may be underreported in large, population based cohorts. ${ }^{(40)}$ Our primary analysis, which only captures the initial chemotherapy and radiotherapy treatments, does not fully reveal the number of treatments that occurred late near end of life. This is reflected in the higher utilization rates seen near the end of life in the 60-day limited survival subset. Lastly, while our study shows the number of patients that received chemotherapy and radiotherapy (versus just chemotherapy or just radiotherapy), it does not show time trends or covariate analysis for the usage of combination therapy.

\section{References}

[1] Mariotto AB, Yabroff KR, Shao Y, Feuer EJ, Brown ML. Projections of the cost of cancer care in the United States: 2010-2020. J Natl Cancer Inst. 2011 Jan 19;103(2):117-28.

[2] Glare P, Virik K, Jones M, Hudson M, Eychmuller $S$, Simes J, et al. A systematic review of physicians' survival predictions in terminally ill cancer patients. BMJ. 2003 Jul 26;327(7408):195-8.

[3] Chow E, Harth T, Hruby G, Finkelstein J, Wu J, Danjoux C. How accurate are physicians' clinical predictions of survival and the available prognostic tools in estimating survival times in terminally ill

\section{Conclusion}

When examining the Florida state-wide cancer registry, the initiation of late chemotherapy and radiation treatments decreased from 1995-2010, but persisted at above a $3 \%$ baseline level in the last 14 days of life. Clinicians may struggle to taper treatment before death, especially in patients with limited survival. Younger, married and male patients were statistically more likely to receive palliative treatments. Insurance and SES did not influence the delivery of radiation, but did impact the use of chemotherapy. More work remains to be explored regarding disease burden and prognostic characteristics that affect the susceptibility to over-aggressive treatments. When defining quality care metrics, it is important to recognize the complexities of death and dying and the potential influences of palliative care in affecting decision-making regarding the delivery of treatment near the end of life.

\section{Acknowledgements}

The Florida cancer incidence data used in this report were collected by the Florida Cancer Data system under contract with the Department of Health (DOH). The views expressed herein are solely those of the author(s), and do not necessarily reflect those of the contractor of $\mathrm{DOH}$.

\section{Author Disclosure Statement}

No competing financial interests exist.

cancer patients? A systematic review. Clin Oncol R Coll Radiol G B. 2001;13(3):209-18.

[4] Christakis NA, Lamont EB. Extent and determinants of error in physicians' prognoses in terminally ill patients: prospective cohort study. West J Med. 2000 May;172(5):310-3.

[5] Oxenham D, Cornbleet MA. Accuracy of prediction of survival by different professional groups in a hospice. Palliat Med. 1998 Mar;12(2):117-8.

[6] Nappa U, Lindqvist O, Rasmussen $\mathrm{BH}$, Axelsson B. Palliative chemotherapy during the last month of life. Ann Oncol. 2011 Nov 1;22(11):2375-80. 
[7] Murillo JR, Koeller J. Chemotherapy Given Near the End of Life by Community Oncologists for Advanced Non-Small Cell Lung Cancer. The Oncologist. 2006 Nov 1;11(10):1095-9.

[8] Emanuel EJ, Young-Xu Y, Levinsky NG, Gazelle G, Saynina O, Ash AS. Chemotherapy Use among Medicare Beneficiaries at the End of Life. Ann Intern Med. 2003 Apr 15;138(8):639-43.

[9] Walasek T, Sas-Korczyńska B, Dąbrowski T, Reinfuss M, Jakubowicz J, Blecharz $P$, et al. Palliative thoracic radiotherapy for patients with advanced non-small cell lung cancer and poor performance status. Lung Cancer. 2015 Feb $1 ; 87(2): 130-5$.

[10] Smith TJ, Temin S, Alesi ER, Abernethy AP, Balboni TA, Basch EM, et al. American Society of Clinical Oncology provisional clinical opinion: the integration of palliative care into standard oncology care. J Clin Oncol Off J Am Soc Clin Oncol. 2012 Mar 10;30(8):880-7.

[11] Stavas MJ, Pagan JD, Varma S, Li B, Kachnic LA. Building a palliative radiation oncology program: From bedside to B.E.D. Pract Radiat Oncol [Internet]. 2016 Sep 13 [cited 2017 Apr 19];0(0). Available from: http://www.practicalradonc. org.proxy.library.vanderbilt.edu/article/S18798500(16)30183-7/fulltext

[12] West L, Cole S, Goodkind D, He W. 65+ in the United States: 2010, United States Census Bureau. [Internet]. [cited 2017 Jun 12]. Available from: https://www.census.gov/content/dam/Census/ library/publications/2014/demo/p23-212.pdf

[13] Certification Levels [Internet]. [cited 2016 Apr 26]. Available from: http://naaccr.org/Certification/ CertificationLevels.aspx

[14] The Florida Cancer Data System Home Page [Internet]. [cited $2016 \mathrm{Apr}$ 26]. Available from: https://fcds.med.miami.edu/inc/welcome.shtml

[15] Earle CC, Neville BA, Landrum MB, Ayanian JZ, Block SD, Weeks JC. Trends in the Aggressiveness of Cancer Care Near the End of Life. J Clin Oncol. 2004 Jan 15;22(2):315-21.

[16] Guadagnolo BA, Liao K-P, Elting L, Giordano S, Buchholz TA, Shih Y-CT. Use of Radiation Therapy in the Last 30 Days of Life Among a Large Population-Based Cohort of Elderly Patients in the United States. J Clin Oncol. 2013 Jan 1;31(1):80-7.

[17] Tiwana MS, Barnes M, Kiraly A, Olson RA. Utilization of palliative radiotherapy for bone metastases near end of life in a population-based cohort. BMC Palliat Care. 2016;15:2.

[18] Kapadia NS, Mamet R, Zornosa C, Niland JC, D'Amico TA, Hayman JA. Radiation therapy at the end of life in patients with incurable nonsmall cell lung cancer. Cancer. 2012 Sep 1;118(17):4339-45.

[19] Weeks JC, Catalano PJ, Cronin A, Finkelman MD, Mack JW, Keating NL, et al. Patients' Expectations about Effects of Chemotherapy for Advanced Cancer. N Engl J Med. 2012 Oct 25;367(17):161625.

[20] Chen AB, Cronin A, Weeks JC, Chrischilles EA, Malin J, Hayman JA, et al. Expectations About the Effectiveness of Radiation Therapy Among Patients With Incurable Lung Cancer. J Clin Oncol. $2013 \mathrm{Jul}$ 20;31(21):2730-5.

[21] Lewis JM, DiGiacomo M, Currow DC, Davidson PM. Dying in the margins: understanding palliative care and socioeconomic deprivation in the developed world. J Pain Symptom Manage. 2011 Jul;42(1):105-18.

[22] Yabroff KR, Kim Y. Time costs associated with informal caregiving for cancer survivors. Cancer. 2009 Sep 15;115(18 Suppl):4362-73.

[23] Dionne-Odom JN, Azuero A, Lyons KD, Hull JG, Tosteson T, Li Z, et al. Benefits of Early Versus Delayed Palliative Care to Informal Family Caregivers of Patients With Advanced Cancer: Outcomes From the ENABLE III Randomized Controlled Trial. J Clin Oncol Off J Am Soc Clin Oncol. 2015 May 1;33(13):1446-52.

[24] Barnato AE, Herndon MB, Anthony DL, Gallagher PM, Skinner JS, Bynum JPW, et al. Are Regional Variations in End-of-Life Care Intensity Explained by Patient Preferences? Med Care. 2007 May;45(5):386-93.

[25] Voogt E, Heide A van der, Rietjens JAC, Leeuwen AF van, Visser AP, Rijt CCD van der, et al. Attitudes of Patients With Incurable Cancer Toward Medical Treatment in the Last Phase of Life. J Clin Oncol. 2005 Mar 20;23(9):2012-9.

[26] Finucane TE. Care of Patients Nearing Death: Another View. J Am Geriatr Soc. 2002 Mar 1;50(3):551-3.

[27] Matsuyama R, Reddy S, Smith TJ. Why do patients choose chemotherapy near the end of life? A review of the perspective of those facing death from cancer. J Clin Oncol Off J Am Soc Clin Oncol. 2006 Jul 20;24(21):3490-6.

[28] MedCrave. Geriatric oncology: where age is not measured by years. Int Clin Pathol J [Internet]. 2017 Dec 4 [cited 2019 Jun 3]; Volume 5(Issue 4). Available from: http://medcraveonline.com/ICPJL/ ICPJL-05-00136.pdf

[29] Krishnan MS, Epstein-Peterson Z, Chen Y-H, Tseng YD, Wright AA, Temel JS, et al. Predicting Life Expectancy in Patients With Metastatic Cancer 
Receiving Palliative Radiotherapy: The TEACHH Model. Cancer. 2014 Jan 1;120(1):134-41.

[30] Kelly CM, Shahrokni A, Kelly CM, Shahrokni A. Moving beyond Karnofsky and ECOG Performance Status Assessments with New Technologies, Moving beyond Karnofsky and ECOG Performance Status Assessments with New Technologies. J Oncol J Oncol. 2016 Mar 15;2016, 2016:e6186543.

[31] Wright AA, Katz IT. Letting Go of the Rope Aggressive Treatment, Hospice Care, and Open Access. N Engl J Med. 2007 Jul 26;357(4):324-7.

[32] Daugherty CK. Examining ethical dilemmas as obstacles to hospice and palliative care for advanced cancer patients. Cancer Invest. 2004;22(1):123-31.

[33] McGorty EK, Bornstein BH. Barriers to physicians' decisions to discuss hospice: insights gained from the United States hospice model. J Eval Clin Pract. 2003 Aug 1;9(3):363-72.

[34] American Academy of Hospice and Palliative Medicine. Choosing Wisely Campaign ${ }^{\circledR}$ [Internet]. 2013. Available from: http://www.choosingwisely. org/clinician-lists/american-academy-hospicepalliative-care-dont-delay-palliative-care/

[35] Blumenthal D, Abrams M, Nuzum R. The Affordable Care Act at 5 Years. N Engl J Med. 2015 Jun 18;372(25):2451-8.

[36] Burwell SM. Setting Value-Based Payment Goals - HHS Efforts to Improve U.S. Health Care. N Engl J Med. 2015 Mar 5;372(10):897-9.

[37] Ginsburg PB. Spending to Save - ACOs and the Medicare Shared Savings Program. N Engl J Med. 2011 Jun 2;364(22):2085-6.

[38] Temel JS, Greer JA, Muzikansky A, Gallagher ER, Admane S, Jackson VA, et al. Early palliative care for patients with metastatic non-small-cell lung cancer. N Engl J Med. 2010 Aug 19;363(8):733-42.

[39] Wright AA, Zhang B, Ray A, et al. Associations between end-of-life discussions, patient mental health, medical care near death, and caregiver bereavement adjustment. JAMA. 2008 Oct 8;300(14):1665-73.

[40] Jagsi R, Abrahamse P, Hawley ST, Graff JJ, Hamilton AS, Katz SJ. Underascertainment of radiotherapy receipt in Surveillance, Epidemiology, and End Results registry data. Cancer. 2012 Jan 15;118(2):333-41. 